\title{
Model of Eco-Industrial Park Development as a Tool for Fostering Energy Efficient Economy
}

\author{
Evgeniy Tikhanov ${ }^{1 \mathrm{a}}$, Vadim Krivorotov ${ }^{1}$, Aleksey Kalina ${ }^{1}$, and Sergei Erypalov ${ }^{1}$ \\ ${ }^{1}$ Ural Federal University named after the first President of Russia B.N. Yeltsin, 620002, Yekaterinburg, Russia
}

\begin{abstract}
Energy efficiency plays a key role in the development of modern socio-economic systems, such as cities. Energy efficiency can be achieved through creation and development of eco-industrial parks. This article describes the concept of such parks and their peculiar characteristics and provides an overview of research literature on their development, energy efficiency and competitiveness of their resident enterprises. Performance of eco-industrial parks can be evaluated by applying a set of indicators, which demonstrate the competitiveness of park residents. This system of indicators can be used to model the management of ecoindustrial park development. This article also describes a methodological approach to evaluate competitiveness of resident enterprises: the integral index of competitiveness, which synthesizes their current and prospective competitiveness. Comparative analysis (conducted by applying 'PATTERN' method, Planning Assistance Through Technical Evaluation of Relevance Numbers) also takes into account specific indicators of residents' competitiveness. This research uses the methods of static modelling to create an algorithm for building a model which establishes the correlation between the indicators of the park's performance and the level of its residents' competitiveness. The proposed model was applied to develop a program of management for eco-industrial park 'Tagil'.
\end{abstract}

\section{Introduction}

Nowadays developed countries are going through a new wave of industrialization, which is driven by knowledge-intensive innovations and advanced technologies in the humanities and social studies. Such industrialization significantly raises the energy efficiency standards and brings urban space to a totally new level. Thus, energy efficiency encourages qualitative economic growth, gives the competitive edge to the existing and newly established manufacturing enterprises and provides long-term sustainable development of urban areas. Cities and their infrastructure are becoming more efficient, safe, and comfortable.

The key areas of enhancing economic energy efficiency include stimulating the growth of enterprises with low energy intensity; improvement of the infrastructure; cost saving at the stages of production, transportation and consumption of energy. Industrial parks productively combine the above-mentioned measures and are considered as one of the most

a Corresponding author: tjohn90@mail.ru 
efficient forms of production organization in the world. Industrial parks are generally understood as centrally managed areas with well-organized infrastructure, which are intended for establishing new production enterprises. At present there are over twenty thousand industrial parks in over ninety countries of the world.

In many countries of Europe, North America and Asia, industrial parks are seen not only as a tool for attracting private investment, creating new workplaces, increasing tax revenues and diversification of economy but also as means of developing energy efficient economy, implementation of innovations and advanced processing of raw materials.

One of the most promising concepts developed in the recent decades is that of ecoindustrial parks (EIPs). The main difference between EIPs and their industrial counterparts is that management companies follow comprehensive strategies of development, which, apart from improving the performance of resident enterprises, seek to reduce their negative environmental impact. EIPs are expected to meet the following goals: to form a balanced infrastructure; to increase the efficiency of energy and other resources; to create resourcesaving and low waste technologies; to establish partnership relations between enterprises; to curb the environmental pollution; to organize advanced processing of waste and encourage resident companies to reuse waste.

\section{Modern research on eco-industrial parks, energy efficiency and competitiveness of enterprises}

The concept of EIPs emerged in the USA in the early 1990s. It was intended to bring together producers of commodities and services in order to improve their economic performance and at the same time to protect the environment by managing natural resources collectively. Residents of EIPs uphold high standards of energy efficiency and engineering solutions and work together to ensure that the waste of one company provides materials for another while processed materials are used to manufacture the end product. Nowadays such EIPs are successfully developing in such countries as Canada (Hinton); the USA (Reventure Park); Denmark (Kalundborg); Finland (Rantasalmi); China (Dailan, Suzhou, Nanhai); Indonesia (Semerang, Industri Sona Maris); Japan; India; Vietnam; Thailand; and Mexico.

Most specialists consider EIPs as a tool to develop energy efficient economy and as an effective mechanism of providing resident enterprises with a competitive advantage [1-5]. Therefore, it is important to develop a universal model for management of EIPs' development. The key goals in this process should be to make EIPs more energy efficient and to improve their residents' competitiveness.

Competition is the main driving force of development in market business models and the relevant research literature provides a wide range of approaches to competitiveness evaluation. The existing approaches can be divided into the following groups:

1. Competitive strategy methods: for example, the matrix of the Boston Consulting Group 'Market Share'/'Market Growth' [6]; McKinsey's matrix 'Competitive Strength of a Business Unit/Industry Attractiveness' [7]; M.E. Porter's matrix 'Strategic Objective/Strategic Advantage' [8];

2. Methods based on the value chain concept. This approach was first introduced by M. Porter [9] and then it was developed by a number of other famous researchers such as G. Gereffi [10] and J. Humphrey [11];

3. Approaches and methods which take into account competitiveness of production [12, 13 and others];

4. Methods based on estimation of the business value [14, 15 and others];

5. Methods which are based on the game theory and focus on the strategies of choosing optimal behaviour of business entities [16-19 and others]; 
6. Integrated methods.

These days, however, there is no single approach to evaluation of competitiveness or energy efficiency. As a rule, the latter is evaluated according to a set of indicators, which are determined individually for each specific case. In general, we can identify two main approaches to selecting such systems of indicators.

The first approach divides all energy efficiency indicators into economic (value) indicators; technical and economic (physical) indicators; and the indicators related to how intensively companies use energy efficient technologies [20,21 and others].

The second approach classifies energy efficiency indicators according to types of business activity: it deals with specific industries and with the combinations of different types of activities inside these industries as well as their energy intensity. Such approach is applied, for instance, in the methodology of Asia Pacific Research Center [22]; in the projects of the International Energy Agency [23, 24]; the French Environment and Energy Management Agency (ADEME) [25] and many others.

Another method which is widely applied for evaluating energy efficiency is data envelopment analysis. It is based on comparative analysis of complex technical, economic and social systems. It was introduced by M.J. Farrell [26] and developed by A. Charnes, W.W. Cooper, R.D. Banker [27, 28], and other specialists. It is also applied by Yi-Ming Weia [29], K. Mukherjee [30], and B. Ang [31].

\section{System of indicators characterizing competitive growth of resident enterprises}

To systematize the advantages gained by residents of EIPs the factors of their success can be divided into the three major groups:

1. 'Internal' factors, that is, conditions enhancing the creation and further development of energy efficient enterprises. This group of factors include technology intensive infrastructure; organization of material and energy flows between the residents; open access to information about the waste production, the needs of the EIP's residents in raw materials and the energy they use;

2. Local factors, that is, geographical and logistical advantages of the host area, available human, material, and energy resources;

3. Regional factors, that is, the advantages of locating resident enterprises on the territory of a specific country or region. These include such factors as state support and a favourable investment climate.

We can use a system of quantitative indicators to evaluate and analyze the impact of the above-described factors on competitiveness of enterprises. The analysis of the indicators characterizing the performance of an EIP allows us to develop a complex of management measures to enhance its growth and to create a program of its development by taking into account the real needs of the existing residents.

These indicators can be divided into the two major groups:

1. The indicators which correspond to the 'internal' factors of an EIP's energy efficiency;

2. The indicators which correspond to the external factors (local and regional).

The system of indicators proposed in this paper is shown in Figure 1 and includes nine groups of indicators:

1. Eco- and energy efficiency. Resident enterprises should be using cutting-edge energy saving and environmentally friendly technologies and form closed non-waste production cycles within the framework of a single manufacturing chain or similar kinds of activity. All this would enable them to optimize their industrial processes, enhance their resource efficiency, save the waste disposal costs and the costs of procuring the necessary materials. 


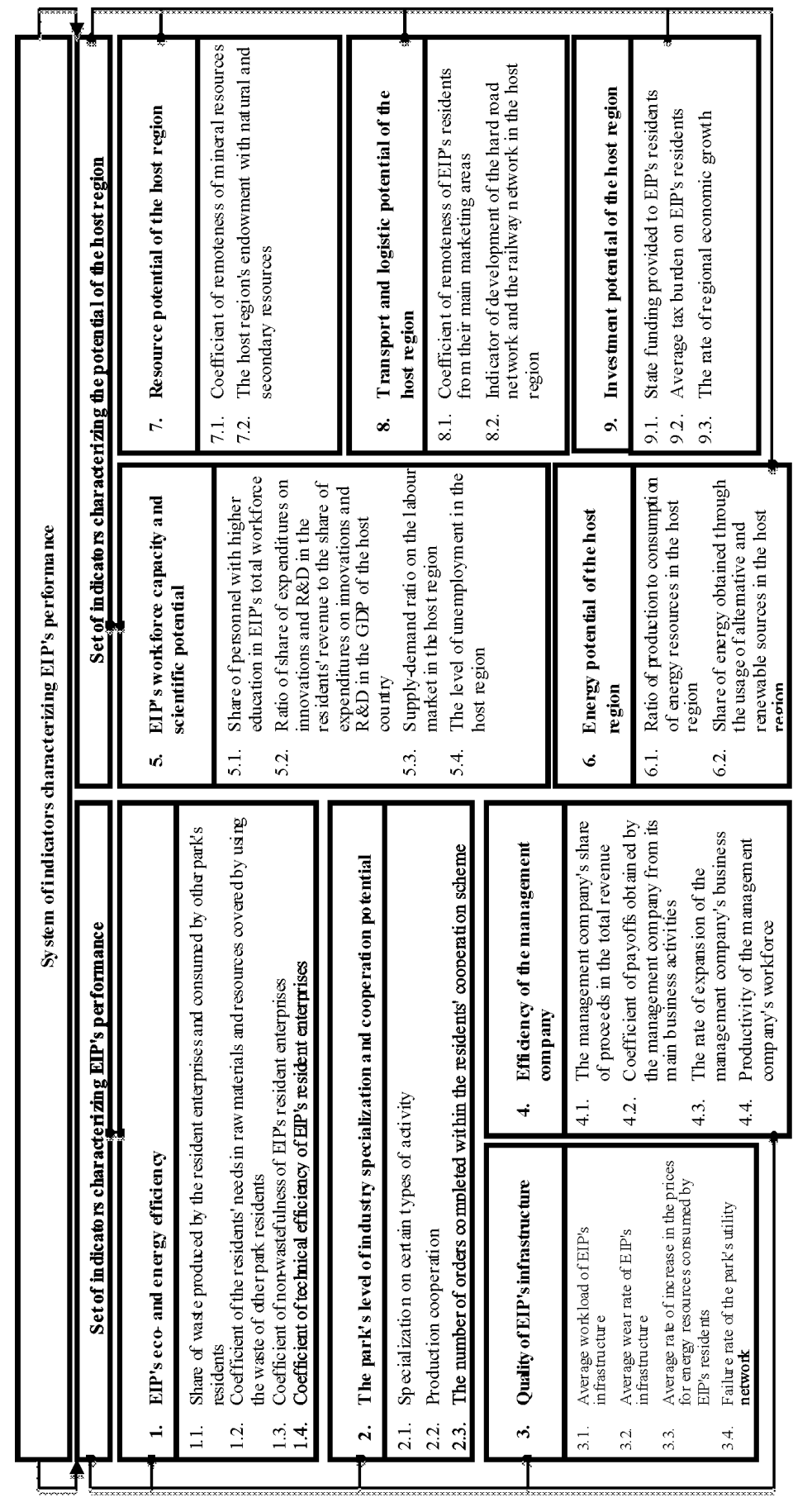

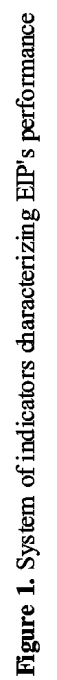

2. Industry specialization and cooperation potential. These are indicators which reflect the potential of the park and its residents regarding their ability to establish long-term economic relations and conduct joint or technologically related production.

3. The quality of the park's infrastructure. These indicators characterize the park's key asset: its engineering, transport and manufacturing infrastructure. They determine time and 
financial expenditures of the residents at the initial stage of the park's development and significantly affect their level of operational expenditures.

4. Efficiency of the park's management company. This group of indicators characterizes the quality of the management company's services provided according to the 'single window' principle, which is of paramount importance for ensuring competitiveness of resident enterprises.

5. Workforce capacity and scientific potential of the host region. These indicators characterize the available workforce, including highly qualified personnel; the quality of the regional educational system; innovative and intellectual potential of the region.

6. Energy potential of the host region. This group of indicators reflects the amount of available energy resources; the availability of alternative and renewable energy sources (for example, wind power generation, hydropower industry, and solar cell panels).

7. Resource potential of the host region. These indicators characterize the availability of natural and secondary mineral resources in the host region, which can be used by resident companies and determine the industrial specialization of this region.

8. Logistical potential of the host region. These indicators characterize the location of the park in relation to the available transport network. The quality of the transport network has a significant impact on the performance of resident companies.

9. Investment potential of the host region. These indicators correspond to the investment climate of the host region, that is, the environment for business and the tools for supporting investment activities.

The above-described system of indicators allows management companies to conduct a comprehensive analysis of their investment sites, evaluating their key advantages and drawbacks. Management companies can also compare specific indicators of the park in question with those of its competitors and thus identify the areas for further improvement. Moreover, this system can be used to elaborate an EIP development program aimed at enhancing the residents' competitiveness.

\section{Methodological approach to evaluation of the resident enterprises' competitiveness}

Another element of the proposed model is the methodological approach to evaluation of the resident enterprises' competitiveness. These authors suggest considering competitiveness as a synthesis of current and prospective competitiveness.

Current competitiveness comprises the energy efficiency the enterprise has already achieved and its financial stability.

Prospective competitiveness (competitive potential) corresponds to the enterprise's capability of maintaining and increasing its competitiveness in the future taking into account its actual dynamics and the degree of risk attached to this enterprise's activity.

In order to link these two values together in one indicator, we need to apply the geometric mean formula (Formula 1) (this method has already been applied by these authors to solve similar problems $[32,33])$ :

$$
K=\sqrt{K_{C} \times K_{P}},
$$

where $K$ is the integrated index of competitiveness;

$K_{C}$ is the indicator of the enterprise's current competitiveness;

$K_{P}$ is the indicator of its prospective competitiveness.

To evaluate competitiveness of a business unit we need to compare the relevant indicators of its activity with those of its competitors, which are assumed as the basic or reference model (Formula 2): 


$$
K_{i}=\frac{C_{i}}{\mathrm{C}_{\text {basic }, i}},
$$

where $K_{i}$ is the value of the $i$ indicator of the company's competitiveness;

$\mathrm{C}_{i}$ is the value of the $i$ coefficient of the company's competitiveness;

$\mathrm{C}_{\text {basic, } i}$ is the basic (reference) value of the $i$ coefficient of the company's competitiveness.

Depending on the research objectives, basic indicators can be the indicators characterizing the activity of the main competitor, a group of competing companies, industry-average indicators in this region, country, or a group of countries. When selecting competing companies for the analysis, it is crucial to take into account the types of their business activity and their product range; the territory's specific features; and the range of the companies' activity.

Formula 2 can be interpreted in the following way: the higher is the value of the coefficient, the more competitive is this enterprise in this indicator as compared with its competitors.

Current competitiveness is determined by the indicators of efficiency and financial sustainability (Formula 3) while prospective competitiveness, by the indicators of the enterprise's potential and risk-taking (Formula 4):

$$
K_{C}=\sqrt{K_{E} \times K_{F S}},
$$

where $K_{T}$ is the current competitiveness of the enterprise;

$K_{E}$ is the indicator of its efficiency;

$K_{F S}$ is the indicator of its financial sustainability.

$$
K_{P}=\sqrt{K_{E P} \times K_{R}},
$$

$K_{P}$ is the prospective competitiveness of the enterprise;

$K_{E P}$ is the indicator of the enterprise's potential;

$K_{R}$ is the indicator of the enterprise's level of risk-taking.

Each of the above-described indicators, in its turn, includes three initial estimate indicators. Therefore, the system of indicators characterizing efficiency of enterprises comprises twelve initial indicators, which are then divided into four groups corresponding to the indicators of the companies' current and prospective competitiveness.

\section{Algorithm of building a model of correlation between the indicators of the park's efficiency and the level of competitiveness of its residents}

The acquired quantitative evaluation of the key indicators of the park's efficiency and the indicators of its residents' competitiveness in several retrospective periods enables us to establish the mathematical correlation between the specified values. This will become the basis for further modelling. It is important to mention that to make this model suitable for practical application the following requirements must be met:

1. Functional relationship between competitiveness of the EIP's residents and the indicators of the site's performance can be determined by using widely applied mathematical tools.

2. The starting data must be representative, that is, it should cover a significant period of time. 
3. Final evaluation should include not only the evaluation of specific residents but of the whole group of core residents. This will provide a more objective picture for further development of measures enhancing competitiveness of the largest enterprises.

The model is built according to the following algorithm:

1. Collection of data on a number of consecutive periods. To make the data more representative the calculations of the relevant indicators should cover not less than five equal time periods.

2. Establishing the correlation between the indicator of competitiveness of the core group with each of the indicators of the EIP's performance. To model this relationship we applied the method of correlation and regression analysis. The initial system of models characterizes the correlation between competitiveness of the core group of residents and each of the indicators of the park's efficiency. This system looks the following way:

$$
R_{\mathrm{i}}=f\left(X_{i 1}, X_{i 2}, \ldots, X_{i n}\right)
$$

where $R_{i}$ is the indicator of the core residents' competitiveness, calculated in accordance with the values of the indicators of the $i$ set of indicators;

$X_{i 1}, X_{i 2}, \ldots, X_{i n}$ are the indicators of the $i$ set of indicators.

At this stage we need to choose the mathematical function which would determine the cause-and-effect relationship between the indicators in question and the parameters of this function related to the intensity of this relationship and its direction.

3. To estimate the accuracy of this evaluation we need to analyze the coefficient of regression, the intensity of the relationship, approximation errors and other parameters and to determine the most significant indicators of the park's performance.

4. Exclusion of unreliable models and models contradicting the logic of the process in question.

5. Building the final model, which illustrates the correlation between the core residents' competitiveness and the indicators of the park's efficiency and which excludes the effect of multicollinearity of the explanatory factors. The acquired model can serve as a basic tool to develop a complex of management measures to improve the EIP's performance.

\section{Practical testing of the model for the development of an eco- industrial park}

The proposed model was used to solve a practical task of developing a program for the development of EIP 'Tagil', which is located in Sverdlovsk region (Russia). The project includes horizontally and vertically integrated chemical production companies, which seek to meet high standards of environmental safety and are located in close proximity to raw materials, oil and gas, energy sources, human resources, and diverse market outlets. The correlation between the competitiveness level of the core residents of 'Tagil' and the indicators of this park's performance looks the following way:

$$
R=-0,58+0,14 \times X_{1}+0,31 \times X_{2}+\left(-0,08 \times X_{3}\right)+0,22 \times X_{4}+0,03 \times X_{5},(6)
$$

where $X_{1 \text { is the }}$ non-wastefulness coefficient of the park's residents;

$X_{2}$ is the level of cooperation achieved on the territory of this park;

$X_{3}$ is the coefficient of remoteness of the park's residents from mineral resources;

$X_{4}$ is the state support provided to the park's residents;

$X_{5}$ is the share of energy obtained through the use of alternative and renewable sources on the park's territory. 
Analysis of this correlation shows that the key factors of residents' competitiveness are the following: environmental safety and non-wastefulness of production; close cooperation between the enterprises operating within the framework of a single technological process; and the state funding received by the residents. Therefore, the development of EIPs should prioritize the following strategies:

1. Raising the standards of ecological and energy efficiency of the park's resident enterprises;

2. Enhancing and expanding interfirm cooperation in production, research and marketing;

3. Assistance to residents provided by the management company in order to attract financial and non-financial state support for the development of production on the territory of park 'Tagil'.

\section{Conclusion}

The proposed system of management of the EIP development is targeted at enhancing competitiveness of its residents. It is a practical tool, which can be used by management companies to elaborate a program of the park's development and create favourable conditions for the growth of resident enterprises. Sustainable development of EIPs will contribute to boosting the local and regional energy efficient economy.

\section{Acknowledgements}

This research was supported by the Government of the Russian Federation (Act 211, agreement № 02.A03.21.0006).

\section{References}

1. A.J. Lambert, F.A. Boons, Technovation, 8, 471-480 (2002)

2. M. Dwortzan. The Greening of Industrial Parks. Technology review, 1, 18-19 (1998)

3. Z. Wang, D. Sun, L. Shi, D. Hu, Y.Xu, Annals of the New York Academy of Sciences, 1, 145-153 (2010)

4. D. Emerson, In Business, 3, 14-20 (2003)

5. L. Metzler, M. Lechner, T. Hayes, American City \& County, 1, 14-19 (2002)

6. B. Henderson, The Product Portfolio, https://www.bcgperspectives.com/content/Classics/strategy_the_product_portfolio

7. McKinsey \& Company (2008), http://www.mckinsey.com/insights/strategy/enduring_ideas_the_ge_and_mckinsey_nin e-box_matrix

8. M.E. Porter, Competitive Strategy: Techniques for Analyzing Industries and Competitors (Free Press, 1998)

9. M.E. Porter, On Competition (Boston, 1998)

10. G. Gereffi, A Commodity Chains Framework in Analyzing Global Industries (Durham, 1999)

11. J. Humphrey, Upgrading in Global Value Chains: ILO Working Paper No. 28 (2004)

12. L.N. Chaynikova, V.N. Chaynikov, Competitiveness of the Product (Tambov, 2007)

13. R.A. Fatkhutdinov, Strategic Marketing (Moscow, 2000)

14. T. Copeland, T. Koller, J. Murrin, Valuation: Measuring and Managing the Value of Companies (New-York:, 1995)

15. M.C. Scott, Value Drivers. The Manager's Framework for Identifying the Drivers of Corporate Value Creation (1998) 
16. V. Cerasi, B. Chizzolini, M. Ivaldi, Applied Economics, 34, 2213-2225 (2002)

17. B. Doberman, H. Gatingnon, G. Sargsyan, Using Attraction Models for Competitive Optimization: Pitfalls to Avoid and Conditions to Check: INSEAD Working Papers No. 27 (2006)

18. V. Kadiyali, K. Sudhir, R. Vithala, International Journal of Research in Marketing, 18, 161-186 (2001)

19. S. Sriram, V. Kadiyali. Channel Responses to Brand Introductions: An Empirical Investigation (2007)

20. B.W. Ang, S.Y. Lee, Energy Economics, 16, 83-92 (1994)

21. B.W. Ang, K.H. Choi, The Energy Journal, 18 (3), 59-73 (1997)

22. Energy Efficiency Indicators: A study of Energy Efficiency Indicators for Industry in APEC Economies,

http://aperc.ieej.or.jp/file/2010/9/26/Energy_Efficiency_Indicators_for_Industry_2000. pdf

23. Energy Indicators System: Index Construction Methodology, http://www1.eere.energy.gov/ba/pba/intensityindicators

24. Energy Policies of IEA Countries, http://www.iea.org/publications/freepublications/publication/canada2009.pdf.

25. Indicators to Measure the Contribution of Energy Efficiency and Renewables to the Lisbon Targets, http://www.isi.fraunhofer.de/isi-en/profile/publikationen.php

26. M.J. Farrell, Journal of the Royal Statistical Society, 120, 253-281 (1957)

27. A. Charnes, W.W. Cooper, E. Rhodes, European Journal of Operation Research, 2 (6), 429-444 (1978)

28. R.D. Banker, A. Charnes, W.W. Cooper, Management Science, 30 (9), 1078-1092 (1984)

29. Y-M.Weia, H. Liao, Y. Fan, Energy, 32 (12), 2262-2270 (2007)

30. K. Mukherjee, Energy Economics, 30, 76-96 (2008)

31. P. Zhou, B.W. Ang, Energy Policy, 36, 2911-2916 (2008)

32. V. Krivorotov, A. Kalina, Zh. Belyaeva, S. Erypalov, Proceedings 7th EuroMed Conference of the EuroMed Academy of Business, 827-835 (2014)

33. V. Krivorotov, A. Kalina, S. Erypalov, Zh. Belyaeva, Competitiveness Review, 26 (2) (2016) 